\title{
Therapeutic strategies against muscular dystrophy and related atrophic disorders
}

\author{
Kunihiro Tsuchida*, Masashi Nakatani and Keisuke Hitachi \\ Division for Therapies against Intractable Diseases, Institute for Comprehensive Medical Science (ICMS), Fujita Health University, Toyoake, Aichi 470-1192, \\ Japan
}

\begin{abstract}
Skeletal muscles represent approximately 30-40\% of total body weight and are important for proper movement; whole body homeostasis, including temperature control and metabolism, such as insulin sensitivity and glucose and lipid metabolism; and inter-organ crosstalk. Skeletal muscles are highly plastic and have remarkable regenerative capacity. There are multiple disorders that affect skeletal muscles. Muscular dystrophies are devastating muscular disorders. Atrophy of skeletal muscle is the most prominent pathoetiology of muscular dystrophy. Furthermore, as skeletal muscles are one of the major targets of insulin action, muscular disorders often affect whole body metabolism. With the rapidly aging population worldwide, sarcopenia, characterized by a decline in skeletal muscle tissue mass and muscle strength with aging, is becoming a major problem. Sarcopenia leads to restriction of physical activities, it affects the quality of life, and is sometimes lethal in elderly individuals. Prevention of and interventions against muscular atrophy and related disorders, like genetic disorders such as muscular dystrophy, sarcopenia, and cachexia, are clinically important as they impact millions of older adults and patients. In particular, Duchenne muscular dystrophy is a genetic disorder that is primarily characterized by progressive muscle weakness and loss. In this mini-review, we briefly review the potential therapeutic strategies against Duchenne musclular dystrophies and related atrophic disorders.
\end{abstract}

Muscle wasting disorders such as muscular dystrophies, sarcopenia, and cachexia, induce skeletal muscle atrophy. Muscular dystrophies are devastating disorders and therapies to prevent muscle atrophy and recover skeletal muscle mass and muscle strength are desired.

In the case of Duchenne muscular dystrophy (DMD), the most severe form of muscular dystrophy, dystrophin genes in the $\mathrm{X}$ chromosome are mutated. In DMD, repeated cycles of cell death and regeneration of myofibers are evident, and myofibers are replaced with fat and connective tissues, causing muscle weakness. Cardiac muscles and the diaphragm are also affected, leading to respiratory problems and mortality.

Effective fundamental and radical therapies for DMD are not yet realized [1]. For DMD, restoring dystrophin is the main therapeutic strategy [1]. Further, exon-skipping therapies for dystrophin genes, several nucleotide-based modified chemicals and morpholinos, and adeno-associated virus (AAV)-mediated skipping of dystrophin [2, 3] have revealed promising results for the treatment of DMD. Eteplirsen and NS-065 are still in the clinical trial stage [2]. Furthermore, dual exon skipping of both dystrophin and myostatin is also worth considering as a treatment option for DMD $[3,4]$. Co-delivery of micro-dystrophin and the myostatin/activin antagonist follistatin has also been reported to restore muscle function in the DMD model [5].

In another type of muscular dystrophy, namely, congenital muscular dystrophy, the splicing defect can be corrected by the CRISPR/Cas9 system [6].

With the rapidly aging society worldwide, coping with aging-related disorders has become very important both medically and socially. Sarcopenia, involving a severe loss of skeletal muscle mass, is one of the major disease etiologies related to aging. Although the precise pathophysiology of sarcopenia is still unknown, it impairs the quality of life and is lethal in elderly individuals [7]. Nutritional status is also a problem in sarcopenia [7]. Cachexia is observed in end-stage cancers, chronic obstructive pulmonary disease, chronic kidney disease, heart failure, and severe infectious diseases, leading to weight loss, fatigue, loss of appetite, adipose tissue loss, and muscle wasting $[7,8]$.

Therefore, multiple diseases can lead to muscle atrophy. As effective fundamental and radical therapies against sarcopenia and muscle wasting diseases are not yet available, it is important to establish therapies to prevent skeletal muscle loss.

\section{Myostatin and related cytokines affecting skeletal muscle mass}

Myostatin inhibitors are promising drug candidates for muscle wasting disorders. Myostatin belongs to the transforming growth factor- $\beta$ (TGF- $\beta$ ) superfamily, including TGF- $\beta$ s, activin, growth differentiation factors (GDFs), and bone morphogenetic proteins (BMPs) [9-11]. Among them, myostatin and GDF11 are structurally similar and play an important role in the negative regulation of muscle growth and determine the mass and size of skeletal muscles and their regenerative capacity. In primates, it has been reported that activin A plays a more important role than myostatin in determining

*Correspondence to: Kunihiro Tsuchida, MD, PhD, Division for Therapies against Intractable Diseases, Institute for Comprehensive Medical Science (ICMS), Fujita Health University, Toyoake, Aichi 470-1192, Japan, Tel: +81562-93-9384; Fax: +81-562-93-5791, E-mail: tsuchida@fujita-hu.ac.jp

Key words: muscular dystrophy, muscle atrophy, sarcopenia, myostatin, activin

Received: August 08, 2018; Accepted: August 24, 2018; Published: August 27, 2018 
skeletal muscle mass [12]. Blockade of myostatin and related TGF- $\beta$ superfamily members is a promising therapeutic strategy for restoring muscle mass and strength in muscle wasting disorders like muscular dystrophy, sarcopenia, and cachexia. Myostatin blockers include myostatin antibodies, myostatin propeptide, follistatin and follistatinrelated proteins, soluble myostatin/activin receptors, siRNA against myostatin or myostatin/activin receptors, and chemicals [9]. Several antibodies and antagonists against myostatin have been developed and used to treat muscular wasting $[13,14]$. Furthermore, antibodies against the myostatin receptors such as activin type II receptors (ActRIIB and ActRIIA), namely, bimagrumab (BYM338), and soluble forms of activin receptor-Fc (sActRIIB-Fc), ACE-083 or ACE-031, have a marked effect in increasing skeletal muscle mass [14-17]. A dual anti-ActRIIA/IIB antibody is critical in promoting maximal skeletal muscle hypertrophy because of inhibition of myostatin and related TGF- $\beta$ family members affecting skeletal muscle [16]. A combination of myostatin/activin blockade with the wheel running exercise is effective in correcting aerobic gene expression profiles of dystrophic muscle toward healthy profiles [17]. Anti-activin receptors are also effective for the treatment of sarcopenia $[18,19]$.

Furthermore, follistatin was initially identified as an activin-binding protein to neutralize activin function, and follistatin-related proteins were revealed to inhibit not only activins but also multiple members of the TGF- $\beta$ family, including myostatin and GDF11 [9]. The follistatin gene therapy trial for BMD and sporadic inclusion body myositis has been carried out with improvement of functional recovery [20]. Structure-function relationships of follistatin-activin or follistatinmyostatin complexes may lead to suitable peptides for myostatin inhibition [21].

Interestingly, givinostat, one of the histone deacetylase (HDAC) inhibitors is reported to be effective in reducing fibrotic tissue and fatty degeneration and increases the fraction of muscle tissue in DMD patients [22-24]. HDAC inhibitors play a role in treating muscle wasting, but this mechanism is yet to be determined. Induction of follistatin could be one of the molecular mechanisms for preventing muscle loss [24].

Recent studies have shown that gene transfer of siRNA or short interfering hairpin RNA-induced myostatin inhibition are effective in increasing skeletal muscle mass $[25,26]$. In this scenario, a combination of siRNA-induced myostatin inhibition with exercise or co-administration of ActRIIB-Fc fusion proteins is effective for skeletal muscle homeostasis and skeletal muscle hypertrophy [26,27]. Recently, genome-editing technology has also been applied to treat muscle wasting. CRISPR/ Cas9-mediated disruption of myostatin prevents muscle wasting in vivo [28]. The cutting-edge genome editing technology is rapidly expanding and could be useful for therapy against muscle wasting and treatment of genetic muscular disorders.

LDN-193189, a small-molecule inhibitor chemical, was also reported to inhibit myostatin signaling and promote functional myoblast differentiation [29]. Since these chemicals inhibit multiple TGF- $\beta$ family members, care must be taken to minimize their side effects.

\section{Conclusion}

Muscular dystrophies and sarcopenia affect skeletal muscles and cause muscle atrophy. Currently, effective therapies against them are limited. In DMD, exon skipping of dystrophin genes is effective and promising as clinically applicable therapeutic strategy. TGF- $\beta$ family members, including myostatin and activins, are involved in muscle atrophy, and blockade of their signaling is effective in the recovery of muscle mass and inducing muscle regeneration. Muscle mass recovery through these therapeutic modalities could be promising for genetic muscle diseases and sarcopenia. A combination of exon skipping and inhibition of TGF- $\beta$ signaling could be effective synergistically. Increase of skeletal muscle over a short period may cause an unexpected burden on bones in elderly people. Therefore, care must be taken to choose the proper treatment and to consider the pathology behind the inhibition of TGF- $\beta$ family members for treating muscle atrophy.

\section{Acknowledgments}

This work was supported in part by JSPS KAKENHI (25860151, $16 \mathrm{~K} 08599,17 \mathrm{~K} 01485$ and 17K08646) and Intramural Research Grants (29-4) for Neurological and Psychiatric Disorders of NCNP.

\section{Competing Interests}

We declare no competing interests.

\section{References}

1. Mah JK (2018) An overview of recent therapeutics advances for Duchenne muscular dystrophy. Methods in Molecular Biology 1687: 3-17.

2. Charleston JS, Schnell FJ, Dworzak J, Donoghue C, Lewis S, et al. (2018) Eteplirsen treatment for Duchenne muscular dystrophy: Exon skipping and dystrophin production. Neurology 90: e2146-2146e2154. [Crossref]

3. Lu-Nguyen N, Malerba A, Popplewell L, Schnell F, Hanson G, et al. (2017) Systemic antisense therapeutics for dystrophin and myostatin exon splice modulation improve muscle pathology of adult mdx mice. Mol Ther Nucleic Acids 6: 15-28. [Crossref]

4. Kemaladewi DU, Hoogaars WM, van Heiningen SH, Terlouw S, de Gorter DJ, et al. (2011) Dual exon skipping in myostatin and dystrophin for Duchenne muscular dystrophy. BMC Med Genomics 4: 36. [Crossref]

5. Rodino-Klapac LR, Janssen PM, Shontz KM, Canan B, Montgomery C L, et al. (2013) Micro-dystrophin and follistatin co-delivery restores muscle function in aged DMD model. Human Molecular Genetics 22: 4929-4937.

6. Kemaladewi DU, Maino E, Hyatt E, Hou H, Ding M, et al. (2017) Correction of a splicing defect in a mouse model of congenital muscular dystrophy type $1 \mathrm{~A}$ using a homology-directed-repair-independent mechanism. Nature Medicine 23: 984-989.

7. Marzetti E, Calvani R, Tosato M, Cesari M, et al. (2017) Sarcopenia: an overview. Aging Clin Exp Res 29: 11-17. [Crossref]

8. Cohen S, Nathan JA, Goldberg AL (2015) Muscle wasting in disease: molecular mechanisms and promising therapies. Nat Rev Drug Discov 14: 58-74. [Crossref]

9. Tsuchida K, Nakatani M, Hitachi K, Uezumi A, Sunada Y, et al. (2009) Activin signaling as an emerging target for therapeutic interventions. Cell Commun Signal 7: 15. [Crossref]

10. Hitachi K, Nakatani M, Tsuchida K (2014) Myostatin signaling regulates Akt activity via the regulation of miR-486 expression. International Journal Biochemistry Cell Biology 47: 93-103

11. Lee SJ, Lee YS, Zimmers TA, Soleimani A, Matzuk MM, et al. (2010) Regulation of muscle mass by follistatin and activins. Mol Endocrinol 24: 1998-2008. [Crossref]

12. Latres E, Mastaitis J, Fury W, Miloscio L, Trejos J, et al. (2017) Activin A more prominently regulates muscle mass in primates than does GDF8. Nat Commun 8: 15153. [Crossref]

13. Bogdanovich S, Perkins KJ, Krag TO, Whittemore LA, Khurana TS (2005) Myostatin propeptide-mediated amelioration of dystrophic pathophysiology. FASEB Journal 19: 543-549.

14. Campbell C, McMillan HJ, Mah JK, Tarnopolsky M, Selby K, et al. (2017) Myostatin inhibitor ACE-031 treatment of ambulatory boys with Duchenne muscular dystrophy: Results of a randomized, placebo-controlled clinical trial. Muscle Nerve 55: 458-464. [Crossref]

15. Lach-Trifilieff E, Minetti GC, Sheppard K, Ibebunjo C, Feige JN, et al. (2014) An antibody blocking activin type II receptors induces strong skeletal muscle hypertrophy and protects from atrophy. Molecular Cellular Biology 34: 606-618.

16. Morvan F, Rondeau JM, Zou C, Minetti G, Scheufler C, et al. (2017) Blockade of activin type II receptors with a dual anti-ActRIIA/IIB antibody is critical to promote maximal skeletal muscle hypertrophy. Proceedings National Academy Sciences USA 114: $12448-12453$. 
17. Kainulainen H, Papaioannou KG, Silvennoinen M, Autio R, Saarela J, et al. (2015) Myostatin/activin blocking combined with exercise reconditions skeletal muscle expression profile of mdx mice. Molecular Cellular Endocrinology 399: 131-142.

18. Morley JE (2016) Pharmacologic Options for the Treatment of Sarcopenia. Calcif Tissue Int 98: 319-333. [Crossref]

19. Rooks D, Praestgaard J, Hariry S, Laurent D, Petricoul O, et al. (2017) Treatment of sarcopenia with bimagrumab: results from a phase II, randomized, controlled, proof-ofconcept study. Journal American Geriatrics Society 65: 1988-1995.

20. Mendell JR, Sahenk Z, Malik V, Gomez AM, Flanigan KM, et al. (2015) A phase 1/2a follistatin gene therapy trial for becker muscular dystrophy. Mol Ther 23: 192-201. [Crossref]

21. Walker RG, Czepnik M, Goebel EJ, McCoy JC, Vujic A, et al. (2017) Structural basis for potency differences between GDF8 and GDF11. BMC Biol 15: 19. [Crossref]

22. Bettica P, Petrini S, D'Oria V, D'Amico A, Catteruccia M, et al. (2016) Histological effects of givinostat in boys with Duchenne muscular dystrophy. Neuromuscul Disord 26: 643-649. [Crossref]

23. Shawi F, Perras C, Severn M (2016) Emerging drugs for Duchenne muscular dystrophy in CADTH Issues in Emerging Health Technologies 1-19.
24. Iezzi S, Di Padova M, Serra C, Caretti G, Simone C, et al. (2004) Deacetylase inhibitors increase muscle cell size by promoting myoblast recruitment and fusion through induction of follistatin. Developmental Cell 6: 673-684.

25. Bhattacharya TK, Shukla R, Chatterjee RN, Dushyanth K (2017) Knock down of the myostatin gene by RNA interference increased body weight in chicken. $J$ Biotechnol 241: 61-68. [Crossref]

26. Mosler S, Relizani K, Mouisel E, Amthor H, Diel P (2014) Combinatory effects of siRNA-induced myostatin inhibition and exercise on skeletal muscle homeostasis and body composition. Physiol Rep 2: e00262. [Crossref]

27. Bayarsaikhan O, Kawai N, Mori H, Kinouchi N, Nikawa T, et al. (2017) CoAdministration of Myostatin-targeting siRNA and ActRIIB-Fc fusion protein increases masseter muscle mass and fiber size. Journal Nutritional Science Vitaminology 63: 244-248.

28. Wei Y, Chen Y, Qiu Y, Zhao H, Liu G, et al. (2016) Prevention of muscle wasting by CRISPR/Cas9-mediated disruption of myostatin in vivo. Mol Ther 24: 1889-1891. [Crossref]

29. Horbelt D, Boergermann JH, Chaikuad A, Alfano I, Williams E, et al. (2015) Small molecules dorsomorphin and LDN-193189 inhibit myostatin/GDF8 signaling and promote functional myoblast differentiation. Journal Biological Chemistry 290: 3390-3404.

Copyright: $₫ 2018$ Tsuchida K. This is an open-access article distributed under the terms of the Creative Commons Attribution License, which permits unrestricted use, distribution, and reproduction in any medium, provided the original author and source are credited. 